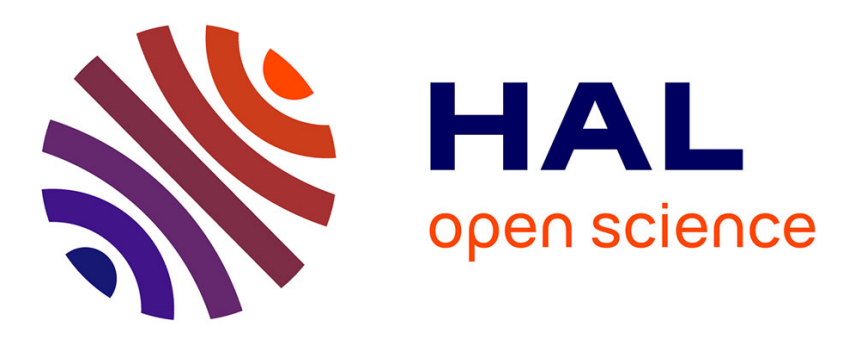

\title{
Could telemedicine enhance traditional medicine practices?
}

Bernard Kamsu-Foguem, Clovis Foguem

\section{To cite this version:}

Bernard Kamsu-Foguem, Clovis Foguem. Could telemedicine enhance traditional medicine practices?. European Research in Telemedicine / La Recherche Européenne en Télémédecine, 2014, vol. 3 ( $\mathrm{n}^{\circ} 3$ ), pp. 117-123. 10.1016/j.eurtel.2014.08.001 . hal-01154611

\section{HAL Id: hal-01154611 \\ https://hal.science/hal-01154611}

Submitted on 22 May 2015

HAL is a multi-disciplinary open access archive for the deposit and dissemination of scientific research documents, whether they are published or not. The documents may come from teaching and research institutions in France or abroad, or from public or private research centers.
L'archive ouverte pluridisciplinaire HAL, est destinée au dépôt et à la diffusion de documents scientifiques de niveau recherche, publiés ou non, émanant des établissements d'enseignement et de recherche français ou étrangers, des laboratoires publics ou privés. 


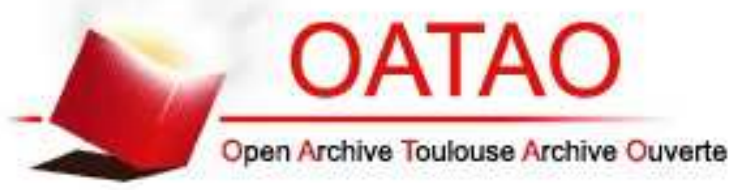

\section{Open Archive Toulouse Archive Ouverte (OATAO)}

OATAO is an open access repository that collects the work of Toulouse researchers and makes it freely available over the web where possible.

This is an author-deposited version published in: http://oatao.univ-toulouse.fr/ Eprints ID: 12006

To link to this article: DOI:10.1016/j.eurtel.2014.08.001 http://dx.doi.org/10.1016/j.eurtel.2014.08.001

\section{To cite this version:}

Kamsu-Foguem, Bernard and Foguem, Clovis Could telemedicine enhance traditional medicine practices? (2014) European Research in Telemedicine / La Recherche Européenne en Télémédecine, vol. 3 (n³). pp. 117-123. ISSN 2212-764X 


\title{
ORIGINAL ARTICLE/REMOTE CONSULTATION \\ Could telemedicine enhance traditional medicine practices?
}

\author{
La télémédecine pourrait améliorer les pratiques de la médecine \\ traditionnelle?
}

\author{
B. Kamsu-Foguem ${ }^{a, *}$, C. Foguem ${ }^{b}$ \\ ${ }^{a}$ EA 1905, laboratory of production engineering (LGP), ENIT-INPT university of Toulouse, 47, \\ avenue d'Azereix, BP 1629, 65016 Tarbes cedex, France \\ ${ }^{\mathrm{b}}$ Center for food and taste sciences (CSGA), UMR 6265 CNRS, UMR 1324 INRA, university of \\ Burgundy, 9E, boulevard Jeanne-d'Arc, 21000 Dijon, France
}

\section{KEYWORDS}

Telemedicine;

Mobile health;

Complementary

medicine;

Therapeutic

education;

Integrated health

center;

Developing countries

\footnotetext{
* Corresponding author.

E-mail address: bernard.kamsu-foguem@enit.fr (B. Kamsu-Foguem).
}

\begin{abstract}
Summary In developing countries, telemedicine and mobile health tools promise to enhance access to high-quality healthcare, to support communication of medical information and to assist pharmacovigilance processes. In this article, we provide some arguments on the potential of telemedicine and mobile health (mHealth) applications to improve the delivery of health care in rural African regions. Specifically, the development of mobile telemedicine could help to lay the foundations of a healthcare approach integrating modern medical knowledge with ancient medical practices on the African continent. Access to information and communication technology (ICT), technical devices or portable media in developing countries is increasingly widespread. This can foster a complementary approach to healthcare, namely in African homebased care (AHC), in which the practice of conventional medicine takes place in an environment where belief in traditional medicine is strong. In the AHC, there are community volunteers who provide primary care and link patients with qualified medical personnel working in the nearest clinics and hospitals. These volunteers have contextual knowledge that is at the frontier of modern and traditional medicine, strongly influencing their practical approach to healthcare. The article proposes an interesting holistic look at potential applications of telemedicine in this context and examines in particular therapeutic and preventive education of toxicological aspects of medicinal plants and communication about the potential side effects of these plants.
\end{abstract}




\section{MOTS CLÉS}

Télémédecine ;

Santé mobile ;

Médecine

complémentaire ;

Éducation

thérapeutique ;

Centre de santé

intégré ;

Pays en

développement
Résumé Les outils de la télémédecine et de la santé mobile offrent de grandes promesses pour ce qui est d'élargir l'accès à une santé de qualité, de soutenir la communication de l'information médicale et d'assister les processus de pharmacovigilance, dans les pays en voie de développement. Dans cet article, nous fournissons des arguments sur le potentiel d'applications de la télémédecine et de la santé mobile (mHealth) pour l'amélioration de la prestation des soins de santé en milieu rural en Afrique. Particulièrement, les développements des moyens mobiles de la télémédecine pourraient permettre de jeter les fondements d'une approche de la santé intégrant les connaissances médicales modernes avec les pratiques médicales ancestrales sur le continent africain. L'accès aux technologies de l'information et de la communication (TIC) dans les pays en développement est de plus en plus répandu; notamment via l'utilisation de dispositifs techniques ou multimédias portables. Ceci peut favoriser une approche complémentaire de soins, en l'occurrence dans les maisons de santé communautaires (MSC), dans lesquels la pratique de la médecine conventionnelle se déroule dans un environnement où la croyance à la médecine traditionnelle est forte. Dans les MSC, on trouve notamment des volontaires communautaires qui offrent des premiers soins et font le lien entre les patients et le personnel médical qualifié exerçant dans les cliniques et les hôpitaux rapprochés. Ces volontaires ont des connaissances qui sont à la frontière de la médecine moderne et de la médecine traditionnelle qui a une forte influence dans leur approche pratique des soins de santé. L'article propose un regard holistique intéressant sur des applications potentielles de la télémédecine dans ce contexte et examine particulièrement l'éducation thérapeutique et préventive avec l'aspect toxicologique des plantes médicinales et la communication sur les potentiels effets secondaires de ces plantes.

\section{Introduction}

A recent study explains the prominence of environmental resources for health service delivery in general [1]. The scale of medicinal plant use can be related to the advantages inherent in the practice of outcome-contingent contracts by African herbal healers [2]. Medicinal plant research has sometimes revealed certain fundamental properties (antimicrobial, anti-inflammatory, antioxidant, anticancer, and anti-diabetic activities) that have led to some progress in medical research and development [3]. We can cite the following examples: the use of phytosterols and phytostanols (for diminishing low density lipoprotein and total cholesterol), black cohosh (for relieving menopausal symptoms) and phytoestrogen extracts (e.g. isoflavones, lignans and coumestans in reducing plasma lipid levels and bone loss) [4]; the medical use of African potato (Hypoxis hemerocallidea or Hypoxis rooperi) for a wide variety of diseases (e.g. intestinal parasites, cough, heart weakness and childhood convulsions) and biomedical evidence has revealed that hypoxis extracts (e.g. glucosides, sterols and sterolins tested in several in vitro and in vivo models as well as in a couple of clinical trials) possess certain pharmacological properties (antimicrobial, antiviral, anti-inflammatory, anti-diabetic, antioxidant, anticancer, cardiovascular and anticonvulsant) [5]. However, there is a lack of sound studies on the comprehensive toxicity of the most used herbal products in African traditional medicine. It is therefore imperative to improve the means for informing people about toxicology aspects and adverse drug reactions of different medicinal plants used in traditional healthcare systems [6].

The challenges presented by the low number of health professionals and unequal distribution of medical infrastructures, within the context of rapid population growth, as well as existing budgetary constraints drive the need for new patient-management models and health care organizations across developing countries.

These new organizations can encourage cooperation and remove barriers between programs conducted within conventional medical frameworks and traditional medicine settings and nurture local competencies, a source of sustainable development. This would provide opportunities to extend knowledge, taking into account the expectations of patients more involved in their healthcare. We live in a pervasive (or ubiquitous) environment where widespread computing allows smart devices to recognize and automatically locate each other. This major breakthrough has been achieved thanks to recent progress in communication, information processing and human-computer interaction technologies. In fact, in both developed and developing countries, healthcare improvements must focus besides care, on prevention, promotion of good health habits and develop community medicine. This is why telemedicine must address these issues, among others, with the following objectives:

- improve access to quality health care services to all individuals regardless of their physical location (remote areas, territories with few medical professionals and dependent persons with multiple chronic conditions);

- optimize the management of scarce medical resources (experts or specialists and infrastructures or devices for the prevention, monitoring and management of complex diseases);

- improve collaboration between health professionals for the implementation of telemedicine procedures, whether in outpatient practices, or in medical or medico-social 
institutions (e.g. collaborative activities for the management of critical situations);

- make the most appropriate coordinated healthcare pathways (e.g. greater regulation of healthcare channels or more standardized care pathways in healthcare provisions) by optimizing health programs within a secure and optimized medical framework.

Telemedicine is a fundamental lever for the development of these new organizations from cost-sharing arrangements to collaborative networks for data and information and knowledge exchanges. It enables organizations' socio-economic constraints to be related with national/international technological-medical advancements. Socio-medical impact includes not only conventional service delivery organizations, but also alternative medical organizations that identify complementary approaches to address contextual native problems. Collaborative management contributes to expressing a coordinated vision and harmonized direction, bonding and stimulating every level of the healthcare organization: mapping primary care (between community-based practice and conventional healthcare activity) with specialized care and rehabilitation services to which complex situations are referred. Telemedicine activities engage in emerging technologies to provide continuity of care in remote regions with an enhancement of professional capabilities through knowledge sharing. Particularly, it provides innovative methodologies to reinforce interdisciplinary practices that continuously improve the skills of medical workers in the fields of conventional and traditional medicines. As a result, there are new opportunities to improve quality of care by expediting disease prevention, management of chronic conditions and continuing medical education of people living and working in geographically remote locations (isolated regions, rural areas or islands).

Telemedicine and mobile health provide valuable tools for bridging between different cultures, traditional medical knowledge and medical information systems, and enables rich and complex African knowledge of diseases and traditional treatment approaches to be shared. We provide compelling reasons that telemedicine and mobile health (mHealth) will enhance rural healthcare delivery in Africa. Access to information and communication technologies (ICT) in developing countries is growing. We make the valid point that African home-based care (AHC) increases the number of people or patients to treat. We also link AHC to African Traditional Medicine (ATM). In Sub-Saharan Africa, $\mathrm{AHC}$ refers to community volunteers who provide home support and report back to medical and nursing staff at clinics and hospitals. They are involved in modern medicine and have a traditional medical background. The paper provides an interesting holistic perspective on telemedicine applications and also examines efforts in developing countries to help bridge the digital divide with the modern age of medical technology.

The paper is divided into four sections. The first section outlines various types of telemedicine and mobile health initiatives with informative characteristics. The second section describes some challenges of herbal medicine practices in an African context. The third section outlines at a high level various policy and practice issues with implementation. The fourth section describes the use of telemedicine in rural community centres. The fifth section integrates aspects concerning the relationships between information technologies and usability considerations. The conclusion delivers remarkable information on healthcare information technology (IT)/policy and provides directions for future research and development of healthcare IT applications.

\section{Telemedicine and mobile health in Africa}

Sharing knowledge between Western health practitioners and traditional practitioners is sometimes difficult, but telemedicine actually opens doors and creates avenues for the traditional medical community to work with modern medical service providers. Viable projects for rural communities create opportunities to integrate traditional and allopathic healthcare issues, for example by collaborating with formal or informal caregiver organisations and by increasing the adoption of ICT frameworks.

Intelligent decision support systems are particularly helpful, since they are able to integrate different components from emergent sensors for data capture through hardware, software, case-based reasoning technologies, communication and suggested recommendations.

For instance, in the Republic of South Africa, a recent project has implemented a remote and sustainable support system for rural healthcare delivery [7]. More traditionally, primary healthcare in South Africa is home-based, established naturally within rural communities in order to provide basic nursing care by formal or informal caregivers to persons in their own homes. The proposed decision support system includes two advanced components: a home-based healthcare delivery model and a telemonitoring patient system. The former component simplifies patient information flow from home-based care workers to a local clinic or hospital while the latter component assists medical staff (nurses and doctors) in deciding the course of intervention or further treatment. Comments from participants and early evaluation results suggest that the proposed system has a positive impact on the quality of healthcare, error elimination, decision assistance and accuracy of alerting of critical cases.

In situations where there are programs that support interactive activities for information sharing between health professionals and traditional practitioners, the advances of communication technology in health care are beneficial. Realization of the telemedicine paradigm should facilitate information sharing amongst health professionals and primary caregivers so that they may adapt their decision support systems to address the specific issues of their patients. The decision support systems can provide advice based on a combination of experienced knowledge and patient numerical data. As such, the local health actors (e.g. disease generalists or specialists, social workers, nutritionists and psychologists) may provide referrals to specialized hospitals and agencies providing home-based care.

Based on the comprehensive characteristics of employed terminology and their meanings, the World Health Organization (WHO) has proposed a classification of key research areas in mHealth [8]: 
- healthcare call centers/health care telephone help line: provision of triage services and health care advice by trained professionals, by telephone;

- toll-free emergency: often used for rapid access to health professionals or staff trained to deliver guidance during medical emergencies;

- public health emergencies: can be defined as the use of mobile devices to react to urgent situations;

- mobile telemedicine: can be defined as the use of functions of a mobile device (e.g., voice, text, data, imaging, or video) for different situations, such as teleconsultation or tele-expertise;

- appointment reminders: comprise services that rely on voice or SMS (short message service) messages sent to patients;

- Community mobilization and health promotion: defined as the use of text messaging for health promotion or alerting target groups of health campaigns;

- patient records: the use of mobile devices to support the treatment of patients, including collecting and displaying patient records;

- information initiatives: comprise services that offer access to health science publications or databases at the point-of-care, by means of portable devices;

- patient monitoring: defined as using technology to manage, monitor, and treat a patient's illness from a distance (e.g., patients suffering from diabetes or cardiac conditions);

- health surveys: the use of mobile devices for collecting and reporting health-related data;

- surveillance: defined as the use of mobile devices for inputting and transmitting data that will be used by surveillance programs to track diseases;

- awareness-raising: comprises the use of health information products, games, or quiz programs to instruct people on relevant health topic;

- decision support systems: defined as software algorithms that help health providers to make their clinical diagnoses at the point-of-care or health managers to take actions based on data collected from health surveys.

The telemedicine system with ATM is described as an integrative medicine system, technically correct because clinical staff use the information sent by volunteers in the field to make clinical decisions. This integrative framework can be applied to health interventions across health domains to explore how and whether available eHealth technologies can support delivery of the associated types of assistance or interventions with the target African populations, e.g. the surveillance strategy (usually considered an eHealth activity). But it can also be used in telemedicine and mobile health tools. The use of surveillance procedures is helpful in emphasizing the fact that it is important for primary caregivers to be involved in analyzing the consequences of public health policy on AHC practices and intelligence reports with regard to drug safety strategy.

\section{Challenges of herbal medicine in Africa}

Nowadays, quality control of herbal medicine and good practices are indispensable for the advancement of the herbal medicine system [9]. Quality problems of herbal medicines can be categorized into: external factors (contamination, adulteration and misidentification) and internal factors (complexity and non-uniformity of the ingredients) [10]. More generally, ensuring and improving patients' safety in integrative healthcare involves the following five research priorities (listed in order of importance) [11]:

- active surveillance projects including vulnerable patients and concomitant use of conventional care;

- attitude to safety among ATM practitioners (i.e. the extent to which safety is integral to clinical practice) and attitude to safety in ATM professional organizations (i.e. the extent to which safety is considered integral in all thinking and decisions);

- influences on, and changes in, public and patient beliefs and attitudes to ATM safety;

- procedures (and their effectiveness) that ATM professional organizations use to ensure continued safe practice by their members;

There is particularly a requirement for the safety monitoring of herbal remedies, and there is a growing necessity to correctly inform consumers about the medicinal products they use. The WHO Drug Dictionary (WHO-DD), the herbal anatomic-therapeutic-chemical (HATC) classification and the system checklist for cross-referencing botanical and vernacular names are particularly valuable tools for improving the operational performance of the safety monitoring programs of herbal medicines for national pharmacovigilance centres [12].

Regulation is fundamental to professionalizing and protecting the image of traditional medicine practice. It will help to eliminate harmful practices and promote the positive aspects of traditional medicine [5]. This will involve the adoption of common diagnostic nomenclature, therapeutic methods, or curriculum [13]. Moreover, in situations where traditional medicine is deemed to be essential, research and development including an evaluation of therapeutic potential and toxicological profile are crucial in fostering patient confidence [14].

Potential herb-drug interactions can cause haemorrhaging, mild serotonin syndrome, induction of mania, exacerbation of extrapyramidal effects, increased risk of hypertension, and decreased or increased blood concentrations or bioavailability of certain blood substances (enzymes, hormones,...) or others drugs [15], glycemic disorders or more severe side effects such as convulsions, medullar aplasia with leucopoenia, and therefore risk of severe infections. Governments have a responsibility to sensitize their traditional medicine practitioners about adverse drug reactions and provide them with the necessary knowledge and training that will promote rational traditional medicine practices [16]. An effective system of surveillance for adverse drug effects, from both a reflexive reporting and a dynamic surveillance viewpoint, must also be established [17]. Computational methods (e.g. surveillance methods) for adverse drug reactions or semantic formalization techniques to remove interoperability barriers, can contribute to ensuring that safe, effective and good-quality traditional medicines are available $[18,19]$. 


\section{Telemedicine in rural community centres}

Generally, rural community development incorporates the improvement of healthcare service through the provision of basic health care for the largest possible number of people. Particularly, the use of telemedicine in rural community centres implies the incorporation of modern information and communication technologies for improving medical services of persons living in rural regions. Rural telemedicine development consists primarily of teleconsultation and telemonitoring activities [20] for community-based health services:

- teleconsultation: the medical community worker and patient are based at a rural site, while the medical professional delivers interactive consultation services from a remote urban location;

- telemonitoring: the medical community worker and patient are based at a rural site, while the medical professional must correctly interpret medical data (clinical, radiological or biological), necessary for a given medical monitoring procedure in the remote workplace.

In both cases, the conditions for deployment are [21]:

- patient identification;

- the requirement to directly or indirectly collect a patient's free and informed consent;

- the authentication of each health personnel involved in the remote consultation;

- the training or preparation of the medical community worker in the use of the telemedicine device;

- noting in the patient record and in the observation record (a summary of the medical act with context, diagnosis and prescription or recommendations).

A telemedicine project is based on dedicated organization of care and professional practices for the target medical environment [22-24]. Clarifications and details on the conditions under which the telemedicine activity is performed must take into account the specificities for the provision of care in the considered region of the world $[25,26]$. Particularly, the implementation of telemedicine programs in developing countries needs to ensure the good understanding of specific social, cultural and economic characteristics. For instance, the African reality clearly shows that natural products are perceived as safe and secure, differentiating them from other pharmaceutical products. This means that patients would tend to want to increase the doses, but when they do so, they might increase risks to their health. Telemedicine activities (e.g. teleconsultation and telemonitoring) may harmonize safety monitoring organization and the effective dissemination of safety rules and procedures. The roles and responsibilities of each actor involved in the telemedicine activity must have formal written terms of description and should entail functional locations, workplace sheets and behavior guidelines with update options. Therefore, each medical or paramedical actor has to act in accordance with the required professional conditions (in force in the country) in order to participate in a telemedicine activity. Furthermore, telemedicine activities must meet some technical requirements for assuring compliance with personal health data protection and the guarantee of fundamental rights and freedoms in practice.
Community health centres play a pivotal role in rural areas in preventive and therapeutic support for local populations. They ensure the social and medical links between conventional hospitals and patients. The medical worker of a community health centre assisting with a telemedicine activity plays an essential role in highlighting real living conditions, actual experiences and expectations of the patient in consultation. As previously mentioned, at an initial stage, the two main telemedicine activities are both the teleconsultation and telemonitoring.

A framework for support in teleconsultation: the community health centre's actor assisting the patient becomes the mediator of the consultation, the relationship between the hospital doctor and the patient, and guarantees the transmission of different exchanges [27].

A framework for support in telemonitoring: the principle of the telemonitoring of patients with chronic diseases (e.g. heart disease, chronic kidney disease and diabetes) is increasingly recognized as essential in meeting the important needs of these patients [28,29].

These professional actors involved in community health centres describe an improved relationship with the patient because of this support of telemedicine activities. As a result, knowledge sharing occurs between the health professionals and the patient and his family. In fact, the family members of patients can provide useful information for the planning and management of health care; in turn they benefit from the interesting care counselling provided by health professionals.

The situation of developing countries requires the deployment of telemedicine projects with low operating costs. mHealth provides the means to increase the use of digital technologies and Internet access around the world. The definition of purchase requirements for a given telemedicine project should also develop guidelines to ensure good levels of access for large numbers of African people. Besides, coherent choices with sustainable considerations can be made for specific operation and maintenance of the medical devices and information systems used in rural conditions. Some direct or indirect funding by the African governments can reduce costs for community health centres and make mHealth devices prices more affordable. In addition, non-governmental organizations and other charitable foundations may provide supplementary budgetary resources for the acquisition of critical materials, devices, and information technology equipment. Hence, the rural African population can have access to a certain number of healthcare services at more reasonable prices.

\section{Discussion}

There is an expectation that mobile phones will facilitate a range of telemedicine activities (cardiology, radiology, nephrology, dermatology, obstetrics, psychiatry and ophthalmology) in Africa [30]. Nevertheless, there may be certain cases or circumstances in which health workers do not necessarily accept mHealth in their routine activities. Furthermore, due to network disruptions that affect the quality of mobile phone and Internet services in Africa, the guarantee of services is not permanent. There are also 
healthcare professionals' organisational barriers to health information technologies [31]:

- structure of healthcare organisations;

- tasks;

- people policies;

- incentives;

- information and decision processes.

Usability issues are a great obstacle to health information technology (IT) acceptance. The health IT usability evaluation model (Health-ITUEM) was designed and used in a number of policy exercises focusing on interactions between the user and tasks in a web-based communication system [32]. Health-ITUEM concepts include:

- perceived ease of use: error prevention, other outcomes, information requirements and memorability;

- perceived usefulness: learnability, competency, perform speed, flexibility/customizability;

- efficiency and effectiveness.

The Health-ITUEM framework has recently been tested and evaluated to provide appropriate and useful understanding and knowledge of adjusted management in the usability issues related to mHealth technology [33]. As the potential inherent in this technology is broadly recognized by global health agencies and industrial practitioners working in the field, evidence-based strategies are needed to provide guidance to implementing organizations, help legitimize mHealth and promote related national government policies [34]. In this respect, improvement measures, which optimize meaningful mHealth utilization and health systems, are required to assist developing countries less advanced in the field. In practice, the strengths and disadvantages associated with each mHealth category can be of a different nature, depending on the level of health workers' involvement, the degree of formality of the organisational structure, the availability of resources, initial arrangements with mobile operators and requirements regarding the application's capabilities [35].

\section{Conclusion}

Telemedicine and mHealth can play an important role in forging strategic links between the different stakeholders working in research issues of traditional, complementary and alternative medicines. Particularly, the effective communication of information on toxicological evaluations of the most frequently used medicinal plants can be important in the safety and monitoring of the African traditional medicine. The promising potential of telemedicine and mHealth applications for an integrated approach in the African healthcare system can significantly contribute to the holistic dimension of traditional societies and local communities with cultural values and ancestral knowledge.

There is evidence to demonstrate that the "informal mobile telecenter' ' besides the formal one, denotes a booming informal business in Africa's mobile telephone sector. This informal business, which is practiced by millions of Africans both in urban and rural areas, involves obtaining a mobile phone and a table in an open area on a street. In addition to buying airtime, the customers can also make calls and cover the costs of communications. It is also possible to borrow mobile phones from relatives or friends and reimburse them the associated costs of communicating the findings to medical members and other healthcare organizations. As a consequence, it is realistic to consider that mobile phones can play an important role (e.g. the educational advantages of telemedicine) in reaching people living on the rural areas.

However, more research is required to learn lessons from socio-cultural and economic contexts for continuous improvement that effectively and efficiently supports primary healthcare services (evaluated from a sustainable user-centred perspective) in remote regions of Africa or others regions of the world [36-39]. Organizational, legal, ethical, conceptual and technological issues are crucial in allowing mHealth services to become widespread throughout the emerging area and particularly with some imperatives for their adoption in Africa [40].

\section{Disclosure of interest}

The authors declare that they have no conflicts of interest concerning this article.

\section{References}

[1] Pouliot M. Relying on nature's pharmacy in rural Burkina Faso: empirical evidence of the determinants of traditional medicine consumption. Soc Sci Med 2011;73(10):1498-507.

[2] Leonard KL. African traditional healers and outcomecontingent contracts in health care. J Dev Econ 2003;71(1):1-22.

[3] Fokunang CN, Ndikum V, Tabi OY, Jiofack RB, Ngameni B, Guedje NM, et al. Traditional medicine: past, present and future research and development prospect and integration in the national health system of Cameroon. Afr J Trad Complement Altern Med 2011;8(3):284-95.

[4] Borrelli F, Ernst E. Alternative and complementary therapies for the menopause. Maturitas 2010;66(4):333-43.

[5] Ncube B, Ndhlala AR, Okem A, Van Staden J. Hypoxis (Hypoxidaceae) in African traditional medicine. J Ethnopharmacol 2013;150(3):818-27.

[6] Edwards IR, Aronson JK. Adverse drug reactions: definitions, diagnosis, and management. Lancet 2000;356(9237): 1255-9.

[7] Barjis J, Kolfschoten G, Maritz J. A sustainable and affordable support system for rural healthcare delivery. Decis Support Syst 2013;56:223-33.

[8] mHealth WHO. New horizons for health through mobile technologies: second global survey on eHealth. The World Health Organization (WHO); 2011.

[9] Sen S, Chakraborty R, Biplab D. Challenges and opportunities in the advancement of herbal medicine: India's position and role in a global context. J Herb Med 2011;1(3-4):67-75.

[10] Zhang J, Wider B, Shang H, Li X, Ernst E. Quality of herbal medicines: Challenges and solutions. Complement Ther Med 2012;20(1-2):100-6.

[11] White A, Boon H, Alraek T, Lewith G, Liu J-P, Norheim A-J, et al. Reducing the risk of complementary and alternative medicine (CAM): Challenges and priorities. Eur J Integr Med 2014;6(4):404-8.

[12] Shetti S, Kumar CD, Sriwastava NK, Sharma IP. Pharmacovigilance of herbal medicines: Current state and future directions. Pharmacog Mag 2011;7(25):69-73. 
[13] Peltzer K. Traditional health practitioners in South Africa. Lancet 2009;374(9694):956-7.

[14] Kamsu-Foguem B, Foguem C. Adverse drug reactions in certain African herbal medicine: literature review and stakeholders' interview'. Integr Med Res 2014, http://dx.doi.org/10.1016/ j.imr.2014.05.001.

[15] Fugh-Berman A. Herb-drug interactions. Lancet 2000;355(9198):134-8.

[16] Shaw D, Graeme L, Duez P, Williamson E, Chan K. Pharmacovigilance of herbal medicine. J Ethnopharmacol 2012;140(3):513-8.

[17] Walji R, Wiktorowicz M. Governance of natural health products regulation: an iterative process. Health Policy 2013;111(1):86-94.

[18] Kamsu-Foguem B, Diallo G, Foguem C. Conceptual graphbased knowledge representation for supporting reasoning in african traditional medicine. Eng Appl Artif Intell 2013;26(4): $1348-65$.

[19] Doumbouya MB, Kamsu-Foguem B, Kenfack H, Foguem C. Telemedicine using mobile telecommunication: towards syntactic interoperability in teleexpertise. Telemat Inform 2014;31(4):648-59.

[20] Simon P, Williatte Pellitteri L. Le décret français de télémédecine: une garantie pour les médecins. Eur Res Telemed 2012;1(2):70-5.

[21] Simon P, Moulin T. L'an III de la télémédecine en France. Eur Res Telemed 2013;2(1):1-4.

[22] Simon P. Tribute to Professor Louis Lareng. Eur Res Telemed 2013;2(2):33-4.

[23] Lareng L. Telemedicine in Europe. Eur J Intern Med 2002;13(1):1-3.

[24] Lareng L. La télémédecine: grandeurs et tristesses. Eur Res Telemed 2013;2(2):79-80.

[25] Bernard, Kamsu-Foguem. Systemic modeling in telemedicine. Eur Res Telemed 2014;3(2):57-65.

[26] Kamsu-Foguem B. Ontological view in telemedicine. Eur Res Telemed 2014;3(2):67-76.

[27] Kamsu-Foguem B, Tchuenté-Foguem G, Allart L, Zennir Y, Vilhelm C, Mehdaoui H, et al. User-centered visual analysis using a hybrid reasoning architecture for intensive care units. Decis Support Syst 2012;54(1):496-509.
[28] Kamsu-Foguem B, Tchuenté-Foguem G, Foguem C. Conceptual graph operations for formal visual reasoning in the medical domain. IRBM 2014, http://dx.doi.org/10.1016/ j.irbm.2014.04.001.

[29] Kamsu-Foguem B, Tchuenté-Foguem G, Foguem C. Using conceptual graphs for clinical guidelines representation and knowledge visualization. Inform Syst Front 2014;16(4):571-89.

[30] Mars M. Telemedicine and advances in urban and rural healthcare delivery in africa. Prog Cardiovasc Dis 2013;56(3):326-35.

[31] Lluch M. Healthcare professionals' organisational barriers to health information technologies - A literature review. Int J Med Inform 2011;80(12):849-62.

[32] Yen PY. Health information technology usability evaluation: methods? models and measures. New York: Columbia University; 2010.

[33] Brown III W, Yen P-Y, Rojas M, Schnall R. Assessment of the Health IT Usability Evaluation Model (Health-ITUEM) for evaluating mobile health (mHealth) technology. J Biomed Inform 2013;46(6):1080-7.

[34] Labrique A, Vasudevan L, Chang LW, Mehl G. H_pe for mHealth: More "y" or " 0 " on the horizon? Int J Med Inform 2013;82(5):467-9.

[35] Sanner TA, Roland LK, Braa K. From pilot to scale: towards an mHealth typology for low-resource contexts. Health Policy Technol 2012;1(3):155-64.

[36] Kamsu-Foguem B, Foguem C. Telemedicine and mobile health with integrative medicine in developing countries. Health Policy Technol 2014, http://dx.doi.org/10.1016/ j.hlpt.2014.08.008.

[37] Kamsu-Foguem B, Tchuenté-Foguem G, Foguem C. Verifying a medical protocol with temporal graphs: The case of a nosocomial disease. Journal of Critical Care 2014;29(4):690e1-9.

[38] Tafin-Kampé K, Kamsu-Foguem B. Acute osteomyelitis due to Staphylococcus aureus in children: What is the status of treatment today? Pediatric Infectious Disease 2013;5(3):122-6.

[39] Tafin-Kampé K. Vitamine D et personnes âgées: enquête auprès de 192 médecins généralistes dans les Hautes-Pyrénées. NPG Neurologie - Psychiatrie - Gériatrie 2014;14(82):221-7.

[40] Adebesin F, Foster R, Kotzé P, Van Greunen D. A Review of Interoperability Standards in $\mathrm{E}$-health and Imperatives for their Adoption in Africa. S Afr Comput J 2013;50:55-72. 